\section{Public access defibrillation}

\section{To the editor:}

In the October 2001 issue of CJEM the Canadian Association of Emergency Physicians Public Access Defibrillation (PAD) Working Group published their position statement in support of PAD programs. ${ }^{1}$ This follows a similar endorsement by the Canadian Heart and Stroke Foundation. ${ }^{2}$ While I applaud the efforts of our association in being proactive with regard to health technology assessment, I feel that a great impediment to PAD programs may come from the fact that most cardiac arrests do not occur in public places.

Survival to cardiac arrest is currently less than 5\% in Ontario. ${ }^{3,4}$ Obviously, something needs to be done. While early defibrillation by first responders (firefighters, police, emergency medical services [EMS]) has been shown to improve survival to cardiac arrest, ${ }^{3}$ the potential impact of a widespread layperson PAD program in the community may not. In a study of 1373 cardiac arrest cases over a 5-year period in the Ottawa region, approximately $85 \%$ of cardiac arrests occurred in private homes, $10 \%$ on the street and only $5 \%$ in large public places. ${ }^{4} \mathrm{~A}$ similar study is under way in 21 Ontario communities. In addition, $2 / 3$ of cardiac arrest victims were found to be in asystole; ${ }^{4}$ those cases could not be helped by defibrillation. Therefore, we can estimate that less than $3 \%$ of all cardiac arrest cases could benefit from such a PAD program. This being said, a person is 3 times more likely to survive if cardiopulmonary resuscitation (CPR) is performed immediately after collapse. ${ }^{5}$ Yet only 3\% of the Canadian population knows how to perform CPR. Al-

For reasons of space, letters may be edited for brevity and clarity. most 9 times out of 10, nothing is being done before EMS arrive. ${ }^{5}$ If only $50 \%$ of cardiac arrest cases were to receive immediate CPR, survival to cardiac arrest could be improved from the current $5 \%$ to over $30 \%{ }^{6}$

With those statistics in mind, and with an international trial under way evaluating the outcome of PAD programs in North America (The PAD Trial), it may be premature to endorse any PAD program at this moment. It may be that if more resources were devoted to increasing the bystander rate of CPR in the population, even better results could be achieved. Such a program would benefit the whole population, not just the few and far between cases of cardiac arrest that occur in public places.

Let's be cautious before we endorse PAD programs.

\section{Christian Vaillancourt, MD}

Research Fellow

University of Ottawa

Attending physician

Ottawa Hospital - Civic Campus

Ottawa, Ont.

\section{References}

1. Canadian Association of Emergency Physicians Public Access Defibrillation Working Group. Public access defibrillation programs [position statement]. CJEM 2001;3(4):267-8.

2. The Heart and Stroke Foundation of Canada. Communiqué submitted to The Standing Committee on Justice and Social Policy, Ottawa, Aug 30, 2001. Available: www.ontla.on.ca/hansard /committee_debates/37/parl/Session2/ju stice/J009.htm\#P595_138991 (accessed 2001 Dec 14).

3. Stiell IG, Wells GA, Field BJ, Spaite DW, De Maio VJ, Ward R, et al. Improved out-of-hospital cardiac arrest survival through the inexpensive optimization of an existing defibrillation program: OPALS study phase II. Ontario Prehospital Advanced Life Support. JAMA 1999;281:1175-81.

4. De Maio V, Stiell I, Wells G, Martin MT, Doherty J, Spaite DW, et al. Potential impact of public access defibrillation based upon cardiac arrest loca- tions [abstract]. Acad Emerg Med 2001;8:415-6.

5. Stiell IG, Wells GA, DeMaio VJ, et al. Modifiable factors associated with improved cardiac arrest survival in a multicenter basic life support/defibrillation system: OPALS Study Phase I results. Ontario Prehospital Advanced Life Support. Ann Emerg Med 1999;33:44-50.

6. De Maio VJ, Stiell IG, Wells GA, Martin MT, Spaite DW, Nichols G, et al, for the OPALS Study Group. The relationship between out-of-hospital cardiac arrest survival and community bystander cardiopulmonary resuscitation rates [abstract]. CJEM 2001;3(2):128.

\section{Propofol in the ED: Check your doses!}

\section{To the editor:}

Doses of 16-33 mg/min for patient-controlled sedation were repeatedly quoted in Dr. Ducharme's commentary. ${ }^{1}$ These doses would be expected to result in general anesthesia within 10 minutes! Propofol infusions in the range of $20-40 \mathrm{mcg} / \mathrm{kg} / \mathrm{min}$ (i.e., $1.5-3 \mathrm{mg} / \mathrm{min}$ for a 70-kg patient) titrated to patient response with boluses of approximately $200 \mathrm{mcg} / \mathrm{kg}(15 \mathrm{mg})$ are more commonly used for procedural sedation. (Product monograph recommendations for surgical diagnostic sedation are for $25-75 \mathrm{mcg} / \mathrm{kg} / \mathrm{min}$ after $0.5-1.0 \mathrm{mg} / \mathrm{kg}$ bolus over 3 to 5 minutes.)

I have difficulty understanding how Dr. Ducharme could author a commentary on propofol that repeatedly quotes infusion rates for sedation that are over 10 times those recommended and used clinically. Although Dr. Ducharme undoubtedly has experience with intermittent mini-dose titration of propofol, his commentary suggests this is not the case with administering propofol infusions. Readers who utilize Dr. Ducharme's recommended propofol infusion rates of $16-33 \mathrm{mg} / \mathrm{min}$ for sedation will quickly find themselves managing an apneic, unconscious patient. Dr. Ducharme's proposed study on pa- 
tient-controlled sedation using propofol in doses of greater than $25 \mathrm{mg} / \mathrm{min}$ would undoubtedly be a short, unpublished study.

I do, however, agree with Dr. Ducharme's comments that mini-dose titration of propofol (20 mg every 45-60 seconds) for sedation during cardioversion minimizes the incidence of apnea and hypotension and allows for rapid emergence for the procedure. In obese patients I have found that positioning the patient in the right lateral decubitus position (recovery position) prior to cardioversion has several advantages.

1. The anterior-posterior placement of the paddles in the obese patient provides a more direct route of energy through the heart and in my experience is associated with a high success rate.

2. Airway obstruction is less likely to occur in the recovery vs. the supine position (as there is a tendency for obstruction to occur as a result of the tongue falling back when the patient is in the supine position).

3. Airway assistance and manoeuvres (jaw thrust, chin lift, positive pressure ventilation) are essentially never required in the recovery position when propofol is titrated properly.

4. Having the patient position himself in the recovery position prior to the procedure saves the staff from manually turning the unconscious patient on his side at the end of the cardioversion.

5. Obstructed respiratory efforts in the supine position generate positive intra-abdominal and negative intra-thoracic pressures, which increases the likelihood of gastric regurgitation and or aspiration.

6. The recovery position is preferable to the supine position for suctioning should regurgitation occur.

\section{Patrick Sullivan, MD}

Associate Professor

Department of Anesthesia

University of Ottawa

Ottawa, Ont.

\section{Reference}

1. Ducharme J. Propofol in the emergency department: another interpretation of the evidence [commentary]. CJEM 2001;3(4):311-2.

\section{[The author responds:]}

I thank Dr. Sullivan for his comments, and am encouraged by his endorsement of mini-dose titration of propofol. I need to correct him in his misunderstanding of my comments about patient-controlled sedation. I did not suggest, nor would I, that infusions of propofol in the order of $16-33 \mathrm{mg} / \mathrm{min}$ be used. The study quoted ${ }^{1}$ showed that patients giving themselves such doses every minute by pushing on a button could not sedate themselves to the point of deep sedation (i.e., loss of protective reflexes). This study was quoted to demonstrate the safety of the minidose approach and was not meant to encourage ongoing infusions.

I am otherwise heartened by this positive input from Anesthesia, and encourage all emergency departments who are hoping to initiate safe procedural sedation policies to work with their anesthesia and emergency colleagues to establish standardized practices.

\section{Jim Ducharme, MD}

Clinical Director

Emergency Medicine

Atlantic Health Sciences Corporation

Saint John, NB

\section{Reference}

1. Smith AF, Thorpe SJ, Cook LB. Patient-controlled sedation using propofol: randomized, double-blind dose refinement. Eur J Anaesthesiol 1999;15: 18-22.

\section{Paediatric CTAS}

\section{To the editor:}

Our centre is one of the busiest urban pediatric emergency departments (EDs) in North America, with more than 65000 visits annually. We implemented the Canadian Paediatric Triage and Acuity Scale (PaedCTAS) 5 months ago [since published as a supplement to the October 2001 issue $^{1}$ of CJEM] and we are generally pleased with it; it has been quite easy to use. However, from the time it was discussed at meetings of the Canadian Paediatric Society and Canadian Association of Emergency Physicians, we have had concerns about the infection category. Our experience is proving that these concerns are real.

Lumping all children "aged 3 to 36 months with fever" in the Level III triage category is unrealistic. Febrile children in this age group represent the most frequent reason for consultation at our centre, and most have relatively benign viral illnesses. If we apply the PaedCTAS consistently, these patients disproportionately expand the Level III triage category, forcing potentially sicker patients with asthma, possible appendicitis or moderate allergic reactions (who should be seen earlier) to wait longer than necessary.

In general EDs with less pediatric experience it may be acceptable to lump all of these children into Level III, but in centres with pediatric triage expertise it is important to redefine this category based on other established criteria, so that some patients can be moved into higher or lower triage levels. Our triage nurses now do this informally without benefit of objective criteria, by placing selected Level III patients ahead of others who arrived earlier. Utility and relevance are critical characteristics of a triage tool and, at least in the infection category, we feel that the PaedCTAS has failed.

The Canadian Emergency Department Triage and Acuity Scale (CTAS) ${ }^{2}$ has become a mandatory triage tool in our provincial EDs. Pediatric centres need an appropriate triage acuity scale to help us gather reliable information and define our acuity, resource level and performance. Before recommending the PaedCTAS as a national stan- 